ERRATA

\title{
Erratum to: $\quad$ Energy-Based Volumetric Rock Destruction Criterion in the Rotary-Percussion Drilling Technology Improvement
}

\author{
V. N. Oparin*, V. V. Timonin**, V. N. Karpov***, and B. N. Smolyanitsky**** \\ Chinakal Institute of Mining, Siberian Branch, Russian Academy of Sciences, Novosibirsk, 630091 Russia \\ *e-mail: oparin@misd.ru \\ **e-mail:timonin@misd.ru \\ ***e-mail:karpov@misd.ru \\ ****e-mail:bsmol@misd.ru
}

Received October 16, 2017

DOI: $10.1134 / \mathrm{S} 106273911801351 \mathrm{X}$

The original article can be found online at:

DOI: $10.1134 /$ S1062739117063114

In the published version there is an error in the formula of air flow rate per second in equation (8). The present form in this erratum is the correct:

$$
Q_{\text {air }}=\frac{Q_{\text {vol }} \rho}{60} .
$$

Further, in the published version there is an error in Fig. 14. The present form in this erratum is the correct:

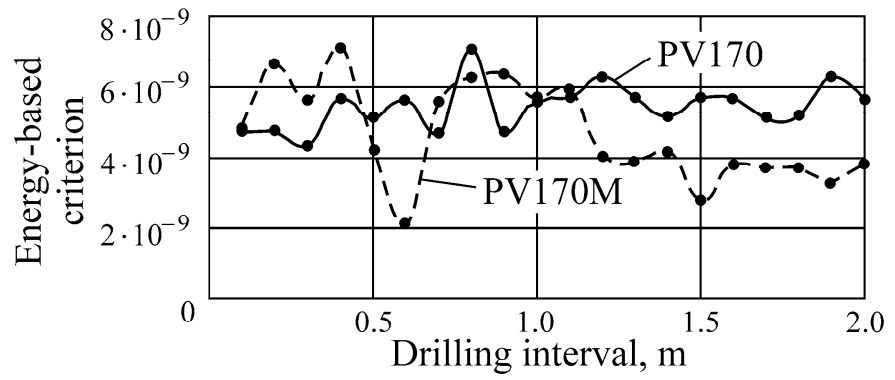

Fig. 14. Criterial indicator $k$ change with the depth during interval drilling in granite (Borok quarry). 